\title{
The Fine Line between Persuasion and Digital Addiction
}

\author{
Deniz Cemiloglu ${ }^{1}(\bowtie)$, Mohammad Naiseh ${ }^{1}$, Maris Catania $^{2}$, \\ Harri Oinas-Kukkonen ${ }^{3}$ and Raian $\mathrm{Ali}^{4}$ \\ ${ }^{1}$ Faculty of Science and Technology, Bournemouth University, UK \\ \{dcemiloglu, mnaiseh\} \& bournemouth.ac.uk \\ ${ }^{2}$ Kindred Group, Sliema, Malta \\ maris.bonello@kindredgroup.com \\ ${ }^{3}$ Oulu Advanced Research on Service and Information Systems, University of Oulu, Finland \\ harri.oinas-kukkonen@oulu.fi \\ ${ }^{4}$ College of Science and Engineering, Hamad Bin Khalifa University, Qatar \\ raali2@hbku.edu.qa
}

\begin{abstract}
Digital addiction is becoming a prevalent societal concern and persuasive design techniques used in digital platforms might be accountable also for the development and maintenance of such problematic behavior. This paper theoretically analyses the relationship between persuasive system design principles and digital addiction in light of theories on behavioral and substance-based addictions. The findings suggest that some of the persuasive design principles, in specific contexts, may trigger and expedite digital addiction. The purpose of this paper is to open a discussion around the potential effects of persuasive technology on digital addiction and cater to this risk in the design processes and the persuasive design itself.
\end{abstract}

Keywords: Digital Addiction, Persuasive System Design, Addiction Theory.

\section{Introduction}

Digital addiction (DA) has emerged as an important research topic over the past few years due to its rising prevalence and public concern about the harmful consequences of excessive use of digital devices and services [1]. While there is no agreed definition or diagnostic criteria for digital addiction, different types of DA such as the internet, social media, and gaming addiction have started to be used and approaches to treat them were proposed [2,3]. For example, Internet Gaming Disorder is stressed within the Statistical Manual of Mental Disorders (DSM-5) for further research [4]. In 2018, the World Health Organization recognized gaming disorder in its International Statistical Classification of Diseases [5].

Despite the lack of a common framework, research suggesting similarities between DA and behavioral and substance-based addictions [6-8] enabled articulating DA through four main conceptualizations. The first focused on time spent on the device and/or platform and the usage style [9]. The second defined DA through DSM-V diagnostic criteria either within compulsive-impulsive spectrum or behavioral addiction [8,10-12], which included symptoms like preoccupation, mood modification, conflict, 
tolerance, and withdrawal. The third defined DA through negative consequences brought to the subject's life [13] and the fourth defined DA as just a symptom of other more profound psychiatric conditions [14]. While such conceptualizations provide a general understanding of DA, the focus on symptoms in explaining DA limits the discussion to the individuals. As addiction is an interwoven connection developed with an entity, the nature of the entity also has an influence on the addictive behavior. This is especially true for DA, as the interactive, intelligent, and personalized nature of digital media make it more possible to attract attention and trigger and reinforce a problematic relationship with it [15]. Hence, software design shall be also studied when studying DA.

In the last two decades, the world economy started to move from a materials economy to an attention economy establishing a market where individual attention is a valuable resource [16]. As human attention is limited, interactive online platforms started to employ immersive and persuasive design techniques to engage users and increase business profit [17]. The use of persuasive design techniques in such platforms raised ethical concerns arguing whether software-mediated persuasion without user informed consent is ethical [18]. Moreover, it is argued that persuasive design techniques intended to increase user engagement or ease task completion for users may also be responsible of excessive usage and in some instances DA [15,19,20].

Understanding the relationship between DA and persuasive design techniques requires an investigation that goes beyond analyzing DA symptoms. That is, one needs to look at the etiological factors that give rise to addictive symptoms in the first place to see whether persuasive design techniques tap on similar mechanisms. Persuasive design techniques are designed to prompt behavioral, cognitive, psycho-social, and other psychological mechanisms to change a person's attitudes and behavior and, while doing so, they may trigger or expedite mechanisms related to addictive behavior. In this paper, we provide a concise review of theories of addiction (Section 2) and persuasive design principles [21] (Section 3) and the contribution of these principles, in certain contexts of use, to hosting and expediting DA and adding to the underlying causes and symptoms of it (Section 4). Finally, we discuss the findings and present directions for future work (Section 5).

\section{Theories of Addiction}

Many theoretical approaches and models have been proposed to explain the development, maintenance, and relapse of addiction. For a collection of reviews, see the work in [22-25]. Each approach highlights different underlying mechanisms in explaining addiction, and there is no single explanation dominating the field [22]. Moreover, the proposed theories and models are not mutually exclusive such that underlying mechanisms highlighted in one can be interrelated with another [24]. This view then suggests that the appearance and maintenance of addiction is a consequence of many integrated mechanisms, in which biological, personal, social, and environmental factors work together [23].

Since DA is argued to show similarities with behavioral and substance-based addictions [6-8], determining the etiological factors of addictive behavior can provide a good 
basis to compare between persuasive systems design principles and DA. Accordingly, we searched the literature for theories in addiction and grouped them under different categories. For the purpose of this paper, we grouped the theories according to eight factors contributing to addiction: biological, predisposition, learning, decision-making, motivation, self-regulation, psycho-social, and contextual. Due to space limitation, a summary is provided for each theory group.

Biological Theories. These theories postulate that addiction is mainly a "brain disease' which results from a disorder in dopamine reward circuit and other circuits involved with conditioning, motivation, and executive functions [26]. It has been shown that drug ingestion activates similar reward circuits in the brain as natural rewards. The fast increase in neurotransmitters caused by drug intake compared to natural rewards may impair reward sensitivity to natural rewards and cause substance dependence [27]. While activation in the reward circuit helps explain initial drug-taking, activation in neural circuits related to motivation, memory, and executive functions help explain compulsion [28]. It has been suggested that improper regulation of dopamine and other neurotransmitters in the neural system reinforces learned associations, enhances the rewarding and motivational value of the substance, and reduces inhibitory control and this, in turn, leads to compulsivity and impulsivity [26].

Predisposition Theories. Individuals may hold certain dispositions which may increase their probability of developing addiction [29]. For example, genetic vulnerability could also arise from comorbid addictive disorders and psychiatric disorders [30] suggesting common causation such that the risk factors that give rise to each disorder may be related [31]. Certain personality traits such as approach-related traits that are associated with sociability, sensation seeking, and impulsivity or avoidance-related traits associated with neuroticism [29], stressful life experience [32], low life satisfaction [33], and socio-demographic characteristics such as education level, occupation, income level [34] may all have an influence on increasing the likelihood of developing addictive behavior.

Learning Theories. Addiction may arise as a learnt behavior through associations made between cues, reinforcements, and responses or through observing others. According to classical conditioning [35], addiction can be explained as a learned response produced when two stimuli are associated together. Addiction develops when the positive-reinforcing value of substance stimuli is implicitly associated with environmental stimuli as it predicts drug ingestion. Operant conditioning, on the other hand, explains addiction as a learned response produced when an association is made between a behavior and its outcome [36]. In time continuous pairing of addictive behavior and the positive outcome may cause the act to become automatic, hence once a goal-directed behavior may turn into a habit, an unconscious response which is no longer linked to the value of the outcome [37]. According to social learning theory, addiction is a learned response produced by observing others [38]. Addiction develops when one associates with peers that show addictive behavior, holds a positive definition of and a positive attitude towards addictive behavior, anticipates positive outcomes as in physiological effects and reaction from others, $[39,40]$. 
Decision-making Theories. Theories on decision-making suggest that individuals decide to engage in addictive behavior, and they base these decisions on cognitive processes. According to the dual-process theory [41], two different types of processing underlie decision-making: the intuitive which is the fast processing based on (heuristics) mental shortcuts, and the rational which is the slow processing based on reflective and deductive reasoning. While intuitive processing saves time and effort in decisionmaking, its heavy reliance on heuristics and its unconscious nature makes it susceptible to biases. From this perspective, addiction might arise from information-processing biases that favor the addictive behavior [42]. For example, Field et al. [43] showed that participants with high levels of cannabis craving were prone to attentional bias, that is, they were showing elevated attention to cannabis cues. Rational decision-making on the other hand is based on analytical processes where decision-makers come to a decision by calculating the cost and benefits of possible options and choose the one that is in their best interest [44]. The term rational here does not imply rationality but suggests that higher-order cognitive processes are involved in coming to that decision. From this perspective, addiction might arise when individuals deliberately assign more value to events that are closer in time while being fully aware of the consequences of the addictive activity in the short and long terms [45]. They may also do that due to missing or incorrect information [46], and when they rationalize their actions and beliefs in a way that favors addictive activity [47].

Motivation Theories. Motivation theories state that addiction may arise due to substance dependence serving as a method to fulfil different motives. Three different motives dominate the literature, (i) achieving pleasure [48], (ii) a means of self-medication, relief distress, meeting pre-existing psychological needs [49,50], and (iii) fulfilling diverse needs such as social identity [51].

Self-regulation Theories. Self-regulation theories state that actions are goal-directed and feedback-controlled such that individuals exert self-control to override impulses and manage their behaviors [52]. In this light, it is suggested that addiction arises from a deficiency in self-control where sub-functions of self-control such as goal setting, self-monitoring, and action planning are individually or collectively impaired $[53,54]$. One might be less likely to self-regulate against addiction if they hold conflicting goals (e.g. I don't want to be an addict versus I want to enjoy another drink), favor gratification goals over self-relevant goals [53], if they cannot monitor their consumption level due to internal distraction or external distractions [55], if they cannot translate their intention to quit to proper action plan [56] and if they do not believe that they are capable of resisting drinking [57].

Psycho-social Theories. Psycho-social theories state that addiction may arise as a result of social connection and social influence [58]. People try to conform to social norms in order to secure social gains and avoid social losses [59] and two types of social norms influence behavior. The first is descriptive norms, the perception of how frequently the behavior is conducted by others and the second is injunctive norms, the perception of approval or disapproval of the defined behavior by others [60]. In this light, addiction may arise from the perception of a high frequency of addictive activities conducted by others and perceived approval of addictive activities within social settings [61]. The concept of identity, a person's sense of who they are could also be a facilitator 
of addiction [51]. Individuals with unmet identity needs may try to construct a sense of self by identifying with addictive activities due to its promise of belonging and respect. Moreover, increased consumption serving to meet identity needs may in time facilitate the individual to identify with the addict role [62].

Contextual Factors Theories. Theories on contextual factors state that vulnerability to addiction can be amplified by broader social environmental factors [63]. These factors could be grouped into three categories: micro-system and community factors, media and advertising factors, and policy and legislation factors. Each factor's influence on the development of addiction may be direct or indirect and is mainly mediated by the individual's characteristics [64]. Moreover, the contextual factors may work on their own or reinforce each other. For example, advertisements on alcohol could reinforce the social norms of drinking.

\section{The Persuasive System Design}

It has been suggested that user behavior in digital environments can be guided by persuasive systems which are defined as "computerized software or information systems designed to reinforce, change or shape attitudes or behaviors or both without using coercion or deception" [21]. Systems can persuade users through both human-computer interaction and computer-mediated communication in which persuasion occurs through other people using the system. Within their persuasive system design (PSD) model, Oinas-Kukkonen, Harjumaa [21] define four categories of design principle which enable a system to be persuasive at an operational level. These include (i) primary task support, design principles that support and ease conducting activities such as reduction and personalization, (ii) dialogue support, design principles that support the achievement of goals while using the system such as praise, rewards and reminders, (iii) social support, design principles that enable motivating certain action through social influence such as social learning and competition and (iv) system credibility support, design principles that make the system more trustworthy, thus more persuasive such as authority and third-party endorsement.

\section{$4 \quad$ Persuasion and Digital Addiction}

In this section, we analyses the association between PSD principles and DA in light of addiction theories discussed in Section 2. We define DA as relationships with technology that meets the diagnostic criteria of behavior addiction (conflict, tolerance, withdrawal symptoms, salience, and relapse) and associated with harm to the person's life. Such a relationship with technology may lead to a usage characterized by being obsessive, impulsive and excessive under the effect of immersion and pressure. This relation can be facilitated through the design and can be analyzed through the addiction theories. Here we have focused on the PSD principles and studied them in light of addiction literature for their potential to facilitate such a relation whether directly or indirectly.

We made an argument about an association between DA and PSD when we found literature to support it. Hence, we do not claim our pairing is comprehensive or that the association we depict is a confirmatory evidence. Our purpose is to shed light on the potential of PSD principles to facilitate DA in certain conditions related to users and 
their context. In reporting the relationship between PSD principles and DA, we differentiated between PSD principles that can be seen themselves as triggers for DA, on one hand, and design principles that can act as facilitators through triggering other cyber behaviors leading to DA. In addition, we considered both addictive actions, i.e. impulsive and hasty cyber actions and addictive behavior in terms of attitudes and habits towards technology. The findings are summarized in Table 1.

Table 1. PSD and DA relationship

\begin{tabular}{|c|c|}
\hline PSD Design Principles & Theories of Addiction \\
\hline Primary Task Support \\
\hline Reduction & BT, SRT, LT, DMT \\
\hline Personalization & SRT \\
\hline Dialogue Support & LT, MT \\
\hline Praise & BT, LT, DMT \\
\hline Rewards & SRT, LT, PST \\
\hline Reminders & LT, DMT \\
\hline Suggestions & DMT \\
\hline Liking & LT \\
\hline Social Support & PST \\
\hline Social Learning & PST \\
\hline Social Comparison & PST \\
\hline Normative Influences & PST \\
\hline Cooperation & PST \\
\hline Competition & PST \\
\hline Recognition & CFT \\
\hline System Credibility Support & \\
\hline Authority & \\
\hline Third-party endorsements & \\
\hline
\end{tabular}

BT: Biological Theories. LT: Learning Theories. DMT: Decision-making Theories. MT: Motivation Theories. SRT: Self-regulation Theories. PST: Psycho-social Theories. CFT: Contextual Factor Theories.

\subsection{Primary Support}

Reduction. A system that reduces effort that users expend with regard to performing their target behavior may be more persuasive.

Biological Theories and Self-regulation Theories: Diminished Self-control. One way the reduction principle could directly relate to DA is through the concept of self-control. Neuroimaging studies showed that addicted individuals had significantly reduced activity in brain regions involved in self-control on tasks that involve response inhibition [65]. Similarly, self-regulation theories explained addictive behavior through one's inability to override impulse [66]. Thus, reducing the steps needed to perform an action may worsen an individual's ability to restrain from performing the action. For example, the ability to link one's credit card to his Android account may reduce the hassle of payment for content within freemium games to a single click. Such reduction principle can increase the likelihood of failing to suppress automatic buy responses and result in large debts, personal distress, and interpersonal conflict [67]. 
Learning Theories: Strengthened Cue-Outcome Association. Because reduction reduces the steps between cue and outcome, the increased proximity between the two can strengthen their association [68]. For example, the appearance of camera icon and ease of access within social media platforms reduces the effort to post photos. Thus, once a person is triggered by an external or internal cue, the ease in taking the action can possibly strengthen the association between posting photos and earning reward in the form of likes. The strengthened association in return can increase the likelihood of repeating the behavior. This example is supported in [69] where the reward and speed of reward play role in forming gambling addiction.

Decision-Making Theories: Biased Decision-making. Reducing the steps in taking an action may speed up the decision-making process. In such cases, individuals may rely on intuitive processing as heuristics allow fast decision-making [41]. However, intuitive processing may make individuals prone to cognitive biases [70]. Biases such as the illusion of control (thinking one can influence the occurrence of an event) and gambler's fallacy (thinking one can predict the probability of an event) are found to be related to excessive gambling [71].

Personalization. A system that offers personalized content or services has a greater persuasive capability.

Self-regulation Theories: Diminished Self-control. Personalization may have an indirect relation to DA through the concept of self-control. Optimizing feeds based on individual interests may encourage individuals to continuously scroll through content and the spontaneous joy experienced while doing so may create a flow experience [72,73]. The authors in [74] demonstrated that people with low self-control are more likely to experience greater flow and more likely to be addicted to the internet, mobile phones and video games. Since flow experience is associated with low self-control [74] providing a personalized content may then arguably tamper an individual's ability to apply self-control and this can, in turn, have an indirect effect on excessive usage.

\subsection{Dialogue Support}

Praise. By offering praise, a system can make users more open to persuasion.

Learning Theories: Reinforcement. The praise principle which can be in the form of word, image, symbols or sound may act like a positive reinforcement as it acknowledges the progress that has been made [75]. While one cannot argue the use of praise will directly lead to DA, sound and music used at online gambling and potentially gaming platforms such as encouraging statements, cheers, and claps may contribute to positive feelings about play and reinforce further rounds and hence loss of control over the play [69].

Motivation Theories: Fulfilling a Heterogenous Need. Praise may also have a negative effect on individuals who overuse digital platforms to promote their self-esteem [76]. For example, authors in [77] suggested that excessive gameplay may result from associations made between self-worth and an avatar's achievements. Thus, having the opportunity to promote self-esteem through the praises on the avatar may act as self-medication and prompt excessive play. 
Rewards. Systems that reward target behaviors may have great persuasive powers.

Biological Theories: Dopamine Hit. Reward principle is believed to be one of the core factors in the development and maintenance of DA. Reward principle is thought to act directly on reward centers in the brain [78]. Each time a reward is received in the form of likes, game points, digital coins, the dopamine circuits in the brain get stimulated resulting in an increase in dopamine release along with other neurochemicals. In time the circuits become habituated to the dopamine, producing a need for higher stimulation which results in increased interaction with digital platforms [79]. This resembles the tolerance symptom of substance based and behavioral addictions.

Learning Theories: Reinforcement. Digital platforms provide multiple rewards in different forms and the association made between use and the positive outcome makes interaction with digital platforms more likely. For example, social approval attained within virtual gaming platforms may act as a social reward further reinforcing the behavior [77]. The reinforcing power of digital rewards increases if the rewards are delivered on a variable ratio schedule which has been proven to be effective in the gambling industry [80]. Rewards in digital platforms such as likes, mentions, game points represent an example of variable-ratio reinforcement due to their unpredictable nature of occurrence. The variable-ratio schedule of such rewards then promotes a high rate of usage as users aim to receive more positive outcomes [81].

Decision-making Theories: Cost-Benefit Analysis. According to reflective decisionmaking theories, individuals apply cost-benefit analysis and select behaviors that are aligned with their self-interest [45]. While doing such analysis it is believed that individuals do temporal discounting in which they assign greater value to events that are closer in time and assign a lower value to future events. While such a tendency is generally not seen as irrational and problematic, problems may arise when the discounting curves get steeper which is typical in addiction [82]. Thus, the presence and the appeal of rewards in digital platforms may contribute to individuals assigning greater value to experiences they have in present, without focusing much on the negative effects in the long run, e.g. reduced academic performance.

Reminders. If a system reminds users of their target behavior, the users will more likely achieve their goals.

Self-regulation Theories: Diminished Self-control. Visual and/or audio alerts may act as external triggers and disrupt individuals from their primary goals making it difficult for them to disengage from digital platforms [83]. Notifications of friend requests, chat messages or comments may hinder self-regulation and this, in turn, can result in loss of control and preoccupation with digital platforms [84]. Preoccupation is one of the main symptoms of behavioral addiction [85]. However, the relationship between notification principle and DA is not as direct, as on the contrary notifications can also reduce preoccupation and repeated checks to see whether one received a new message or alert from the platform.

Learning Theories: Cue to Act and Reinforcement. The learned associations between signals and behavior may lead to habit formation such that signals trigger automatic responses without the awareness of the individual [86]. According to Fogg [87] one of the three important ingredients to initiate behavior is trigger. Thus, in the context of 
digital platforms, notifications may act as triggers that cue an action [88]. Notifications may also act like rewards as they are delivered with variable-ratio reinforcement. Each time a notification is received, a positive expectation may be linked to it causing a "high". If the expectation is not met, this might cause a craving for more [81]. This mimics the relationship between variable-ratio reinforcement on slot machines and excessive gambling [80].

Psycho-social Theories: Social Pressure. Messages and notifications may also be indirectly linked to DA in cases where notifications are received from significant others. In a time where constant connection has become a social norm [89], notification signaling messages from others can make the receiver obliged to respond immediately so that they are not seen in a bad light [90]. As a result, this social pressure might cause people to be preoccupied with social media platforms and neglect their other priorities. The ubiquity of networks that enables notifications to be received wherever and whenever also has the potential to increase this pressure. While social media messaging features such as delivery and read reports and the two ticks indicating that, may help reduce such preoccupations, in some contexts they might worsen the situation e.g. when the sender gets anxious if the receiver reads the message but does not reply [91,92].

Suggestion. Systems offering fitting suggestions will have greater persuasive power.

Learning Theories: Cues for Act and Reinforcement. Just as notifications, suggestions may act as cues for action. While reminders are more about predefined tasks, suggestions are more about exploration and new actions. Consequently, algorithmic suggestions optimized by data characterizing individual interest may promote prolonged digital consumption where success in previous suggestions reinforces further user engagement [93]. Moreover, in addition to the content, the timing and framing are significantly important for the success of suggestions and can be highly optimized through the power of usage data and AI [94].

Decision-making Theories: Biased Decision-making. Artificial intelligence (AI) explanations provided with system suggestions for the purpose of transparency may also indirectly relate to DA. Presenting personalized explanations or explanations that use social proof for content suggestions may trigger biases that favor the addictive behavior. For example, explanations expressing why a video content is suggested (e.g. because your friends viewed it or because your age group viewed it) may activate bandwagon bias [95] which is a mental shortcut for acting in compliance with others and this can imply the correctness of prolonged engagement.

Liking. A system that is visually attractive for its users is likely to be more persuasive.

Decision-making Theories: Biased Decision-making. According to Cialdini [96] liking is one of the six persuasive strategies that can be used to influence and persuade people. One way liking might persuade people is through activating the halo effect bias which is a mental shortcut for judging a trait, e.g. look and attractiveness, in a good light [97]. Similar to the influence of attractive presentation of alcohol through advertisements and product placements [98], visually attractive software, e.g. the online gambling products, may trigger such bias and motivate engagement [99]. In support of this argument, Vaghefi et al. [100] stated that system design which is visually attractive is one of the 
causes explaining prolonged use which suggests a potential indirect link between liking principle and DA.

\subsection{Social Support}

Social Learning. A person will be more motivated to perform a target behavior if they can use a system to observe others performing the same behavior.

Learning Theories: Social Learning. Social learning principle may indirectly relate to DA as being able to observe the relationship between other people's actions and related consequences may reinforce one to model similar behavior to acquire similar outcomes [101]. The authors of [102] found that individuals with game addiction were friends with people who also showed excessive gameplay and suggested that DA could be a result of modelling deviant peers. For example, observing social media influencers getting attention and affection from followers in the form of likes and shares may reinforce others to imitate similar online activity for social reward and this learnt behavior may transform into excessive social media use in time.

Social Comparison. System users will have a greater motivation to perform the target behavior if they can compare their performance with the performance of others.

Psycho-social Theories: Social Comparison: The use of social comparison principle within digital platforms enable individuals to learn about other people's abilities and performances. Such information may increase the likelihood of DA especially for individuals who are high on social comparison orientation (SCO) [103,104]. Because digital platforms are novel platforms with endless social comparison information, individuals high on SCO who base their self-evaluation on comparisons with others may spend longer hours in such platforms than intended in an attempt to decrease the uncertainty they feel regarding their self-concept [103].

Normative Influence. A system can leverage normative influence or peer pressure to increase the likelihood that a person will adopt a target behavior. Provides normative information on the target behavior.

Psycho-social Theories: Normative Influence: This principle may indirectly relate to DA through descriptive norms and injunctive norms as people choose to behave in ways that are common and seen appropriate [60]. For example, Netflix's Top 10 mostwatched video list within your country, updated regularly, can reinforce further usage as descriptive norms and may be seen as implying correctness of the behavior of watching more content. This influence could be coupled with social comparison, in which individual's asses themselves by how well their actions fit with others. In the Netflix example, this could refer to how up to date the user feels compared to his/her peers in terms of knowing the latest movies and documentaries. Another way normative influence principle may have a moderate effect on DA is through injunctive norms which refers to the perception of approved behaviors by others [105]. Injunctive norms act as building blocks of social relationships [60] and because digital platforms enable people to observe and interact with each other, injunctive norms could be easily formed and transferred in this medium. For example, peer pressure on excessive internet usage and 
fast responses may reinforce others to comply with the behavior. This is because not complying with expectations may mean loss of connection with peers [106]. As a result, digital interactions can become a salient part of the individual's life and dominate their minds.

Cooperation. A system can motivate users to adopt a target attitude or behavior by leveraging human beings' natural drive to cooperate.

Psycho-social Theories: The Need to Belong and Peer Pressure: Cooperation principle introduced in some digital platforms may indirectly relate to DA as it generates user commitment to others online. For example, in massively multiplayer online role-playing games (MMORPG) cooperation with others is essential to progress as some missions are designed to be accomplished by group work [107]. Thus, the feeling of responsibility to the group and the peer pressure may reinforce gamers to play more and increase their playtime $[12,108]$. Such a feeling of responsibility may cause preoccupation with the virtual world and increase individual's likelihood of giving up offline activities. This is supported by participant responses in [12] who felt committed to their friends and could not leave them alone in accomplishing a game task.

Competition. A system can motivate users to adopt a target attitude or behavior by leveraging human beings' natural drive to compete.

Psycho-social Theories: Normative Influence and Comparison: Competition is based on self-progress in which individuals are driven by a unidirectional upward push to meet target performance and/or protect one's authority against others [109]. Accordingly, the presence of information on the number of likes, followers on social media platforms, or points, and achievements through badges of leader boards in games may trigger social comparison and encourage competition. Moreover, certain personality traits such as extraversion, assertiveness [110] and narcissism [111] may make individuals prone to competition and increase their engagement with digital platforms. In support, participants in [112] stated that they viewed competition as trigger for addiction.

Recognition. By offering public recognition for an individual or group, a system can increase the likelihood that a person/group will adopt a target behavior.

Psycho-social Theories: Identity: The use of the recognition principle at digital platforms may indirectly relate to DA especially for individuals with low self-esteem. This is because individuals with low self-esteem might be using digital platforms to promote and enhance their self-concept which they find harder to do at offline settings [77,113]. Thus, the respect and reputation that these people receive from social media and gaming platforms in the form of likes, points, awards may help individuals to avoid negative feelings and satisfy their self-esteem needs which in turn can explain their overuse.

\subsection{System Credibility Support}

Authority. A system that leverages roles of authority is more persuasive.

Psycho-social Theories: Normative Influence. Influencers can be perceived as authority figures of social media platforms and promotions run by these platforms (e.g. YouTube Creator Awards) may encourage such perception. Technology companies can rely on 
celebrities and influencers for promoting new features in the apps and games which can act as a trigger for using them by users in a hasty style and without thinking of consequences. For example, when live streaming is presented with a demo showing a celebrity using the features, concerns like privacy and risks become lesser in comparison to the normative influence that demo has created.

Third party Endorsements. Third-party endorsements, especially from well-known and respected sources, boost perceptions on system credibility.

Contextual Factor Theories: Advertisements. Marketing activities may reinforce vulnerability to DA as over-use of digital experiences may be portrayed in a favorable way through advertisements and product placements. This influence may come about in two ways, first advertisements may reinforce popular culture norms and second advertisements may act as cues for addictive activity [114,98].

\section{Conclusion}

The present paper is one of the first attempts to examine the relationship between persuasive design techniques and DA. From the discussion, we can hypothesize that certain PSD principles such as reduction, reward and social comparison may have a more direct effect on DA and other principles such as personalization and liking may have a more moderating effect. However, the differentiation made between direct and moderating effect of PSD principles should be treated as hypotheses that need to be addressed in future research. Overall, the purpose of this paper is not to argue causation but rather to open a discussion around the potential effects of PSD principle on DA in certain context and modality of usage. The paper does not discuss whether PSD principles trigger, worsen or contribute to DA. It is also possible that the relationship between persuasive design techniques and DA might also be explained by additional factors given that the digital products hold unique characteristics in comparison to addictive substances, e.g. their intelligent, interactive, personalized, and real-time nature. Nevertheless, analyzing the potential role of persuasive design in triggering and/or expediting DA from the lens of addiction theories is a start to discuss behavioral, cognitive, psycho-social, and other psychological mechanisms that may be involved in the development and maintenance of addictive behavior in the digital space. Identifying such mechanisms can also facilitate developing frameworks to design for responsible addictive technology through proactive (e.g. psychometric tests) and reactive measures (e.g. selfregulation tools).

Acknowledgments. This work has been partly supported by Kindred Group - Division of Responsible Gaming and Research, through a match-funded $\mathrm{PhD}$ project titled "Responsibility by Design: the Case of Online Gambling”. 


\section{References}

1. Cheng, C., Li, A.Y.-l.: Internet addiction prevalence and quality of (real) life: A meta-analysis of 31 nations across seven world regions. Cyberpsychology, Behavior, and Social Networking 17(12), 755-760 (2014). https://doi.org/10.1089/cyber.2014.0317

2. Winkler, A., Dörsing, B., Rief, W., Shen, Y., Glombiewski, J.A.: Treatment of internet addiction: a meta-analysis. Clinical psychology review 33(2), 317-329 (2013). https://doi.org/10.1016/j.cpr.2012.12.005

3. Gioia, F., Boursier, V.: Treatment of internet addiction and internet gaming disorder in adolescence: a systematic review. In: Multifaceted approach to digital addiction and its treatment. pp. 157-176. IGI Global, (2019). https://doi.org/10.4018/978-1-5225-8449-0.ch008

4. American Psychiatric, A.: Diagnostic and statistical manual of mental disorders (DSM-5®). American Psychiatric Pub, (2013)

5. World Health, O.: ICD-11 for mortality and morbidity statistics (2018). (2018).

6. Kuss, D.J., Griffiths, M.D.: Internet and gaming addiction: a systematic literature review of neuroimaging studies. Brain sciences 2(3), 347-374 (2012). https://doi.org/10.3390/brainsci2030347

7. Olsen, C.M.: Natural rewards, neuroplasticity, and non-drug addictions. Neuropharmacology 61(7), 1109-1122 (2011). https://doi.org/10.1016/j.neuropharm.2011.03.010

8. Young, K.S.: Internet addiction: The emergence of a new clinical disorder. Cyberpsychology \& behavior 1(3), 237-244 (1998). https://doi.org/10.1089/cpb.1998.1.237

9. Johansson, A., Götestam, K.G.: Internet addiction: characteristics of a questionnaire and prevalence in Norwegian youth (12-18 years). Scandinavian journal of psychology 45(3), 223-229 (2004). https://doi.org/10.1111/j.1467-9450.2004.00398.x

10. Block, J.J.: Issues for DSM-V: Internet addiction. The American Journal of Psychiatry 165(3), 306-307 (2008). https://doi.org/10.1176/appi.ajp.2007.07101556

11. Beard, K.W.: Internet addiction: A review of current assessment techniques and potential assessment questions. CyberPsychology \& Behavior 8(1), 7-14 (2005). https:// doi.org/ 10/1089/cpb.2005.8.7

12. Beranuy, M., Carbonell, X., Griffiths, M.D.: A qualitative analysis of online gaming addicts in treatment. International Journal of Mental Health and Addiction 11(2), 149-161 (2013). https://doi.org/10.1007/s11469-012-9405-2

13. Lemmens, J.S., Valkenburg, P.M., Peter, J.: Development and Validation of a Game Addiction Scale for Adolescents. Media Psychology 12(1), 77-95 (2009). https:// doi.org/ $10.1080 / 15213260802669458$

14. Kardefelt-Winther, D.: The moderating role of psychosocial well-being on the relationship between escapism and excessive online gaming. Computers in Human Behavior 38, 68-74 (2014). https://doi.org/10.1016/j.chb.2014.05.020

15. Ali, R., Jiang, N., Phalp, K., Muir, S., McAlaney, J.: The Emerging Requirement for Digital Addiction Labels. In: Fricker, S.A., Schneider, K. (eds.) Requirements Engineering: Foundation for Software Quality, Cham, 2015// 2015, pp. 198-213. Springer International Publishing. https://doi.org/10.1007/978-3-319-16101-3_13

16. Goldhaber, M.H.: The attention economy and the net. (1997). https://doi.org/10.5210/ fm.v2i4.519

17. Hogan, E.A.: The Attention Economy: Understanding the New Currency of Business. In. Academy of Management Briarcliff Manor, NY 10510, (2001). https:// doi.org/ 10.5465/ ame.2001.5898765 
18. Atkinson, B.M.C.: Captology: A Critical Review. In: Ijsselsteijn, W.A., de Kort, Y.A.W., Midden, C., Eggen, B., van den Hoven, E. (eds.) Persuasive Technology, Berlin, Heidelberg, 2006// 2006, pp. 171-182. Springer Berlin Heidelberg. https://doi.org/10.1007/11755494_25

19. Alrobai, A., Phalp, K., Ali, R.: Digital Addiction: A Requirements Engineering Perspective. In: Salinesi, C., van de Weerd, I. (eds.) Requirements Engineering: Foundation for Software Quality, Cham, 2014// 2014, pp. 112-118. Springer International Publishing. https:// doi.org/ 10.1007/978-3-319-05843-6_9

20. Kuonanoja, L., Oinas-Kukkonen, H.: Recognizing and Mitigating the Negative Effects of Information Technology Use: A Systematic Review of Persuasive Characteristics in Information Systems. In: Müller, S.D., Nielsen, J.A. (eds.) Nordic Contributions in IS Research, Cham, 2018// 2018, pp. 14-25. Springer International Publishing. https:// doi.org/1 0.1007 1978-3-319-96367-9_2

21. Oinas-Kukkonen, H., Harjumaa, M.: Persuasive systems design: Key issues, process model, and system features. Communications of the Association for Information Systems 24(1), 28 (2009).

22. West, R.: EMCDDA Insights: Models of addiction. Publications Office of the European Union. Luxemburg (2013).

23. West, R.: Theories of addiction. Addiction 96(1), 3-13 (2001). https://doi.org/ 10.1046/ j.1360-0443.2001.96131.x

24. Kovac, V.B.: The more the 'Merrier': A multi-sourced model of addiction. Addiction Research \& Theory 21(1), 19-32 (2013). https://doi.org/10.3109/16066359.2012.691581

25. Elster, J., Skog, O.-J.: Getting hooked: Rationality and addiction. Cambridge University Press, (1999)

26. Volkow, N.D., Wang, G.-J., Fowler, J.S., Tomasi, D., Telang, F.: Addiction: beyond dopamine reward circuitry. Proceedings of the National Academy of Sciences 108(37), 1503715042 (2011). https://doi.org/10.1073/pnas.1010654108

27. Volkow, N.D., Fowler, J.S., Wang, G.J.: Role of dopamine in drug reinforcement and addiction in humans: results from imaging studies. Behavioural pharmacology 13(5), 355-366 (2002).

28. Volkow, N.D., Fowler, J.S.: Addiction, a disease of compulsion and drive: involvement of the orbitofrontal cortex. Cerebral cortex 10(3), 318-325 (2000). https://doi.org/10.1093/cercor/10.3.318

29. Munafo, M.R., Zetteler, J.I., Clark, T.G.: Personality and smoking status: A meta-analysis. Nicotine \& Tobacco Research 9(3), 405-413 (2007). https://doi.org/10. 1080/ 14622200701188851

30. Goodman, A.: Neurobiology of addiction: An integrative review. Biochemical pharmacology 75(1), 266-322 (2008). https://doi.org/10.1016/j.bcp.2007.07.030

31. Kendler, K.S., Prescott, C.A., Myers, J., Neale, M.C.: The structure of genetic and environmental risk factors for common psychiatric and substance use disorders in men and women. Archives of general psychiatry 60(9), 929-937 (2003). https://doi:10.1001/archpsyc.60.9.929

32. Keyes, K.M., Hatzenbuehler, M.L., Hasin, D.S.: Stressful life experiences, alcohol consumption, and alcohol use disorders: the epidemiologic evidence for four main types of stressors. Psychopharmacology 218(1), 1-17 (2011). https://doi.org/10.1007/s00213-0112236-1

33. Zullig, K.J., Valois, R.F., Huebner, E.S., Oeltmann, J.E., Drane, J.W.: Relationship between perceived life satisfaction and adolescents' substance abuse. Journal of Adolescent Health 29(4), 279-288 (2001). https://doi.org/10.1016/S1054-139X(01)00269-5 
34. Pennanen, M., Broms, U., Korhonen, T., Haukkala, A., Partonen, T., Tuulio-Henriksson, A., Laatikainen, T., Patja, K., Kaprio, J.: Smoking, nicotine dependence and nicotine intake by socio-economic status and marital status. Addictive Behaviors 39(7), 1145-1151 (2014). https://doi.org/10.1016/j.addbeh.2014.03.005

35. Pavlov, I.P.: The work of the digestive glands. Charles Griffin, (1902)

36. Skinner, B.F.: Science and human behavior. Simon and Schuster, (1965)

37. Wood, W., Rünger, D.: Psychology of habit. Annual review of psychology 67 (2016). https://doi.org/10.1146/annurev-psych-122414-033417

38. Bandura, A.: Social cognitive theory: An agentic perspective. Annual review of psychology 52(1), 1-26 (2001). https://doi.org/10.1146/annurev.psych.52.1.1

39. Akers, R.L., Krohn, M.D., Lanza-Kaduce, L., Radosevich, M.: Social Learning and Deviant Behavior: A Specific Test of a General Theory. In: McCord, J., Laub, J.H. (eds.) Contemporary Masters in Criminology. pp. 187-214. Springer US, Boston, MA (1995). https:// doi.org/10.1007/978-1-4757-9829-6_12

40. Akers, R.L., Cochran, J.K.: Adolescent marijuana use: A test of three theories of deviant behavior. Deviant Behavior 6(4), 323-346 (1985). https://doi.org/10.1080/ 01639625. 1985.9967683

41. Evans, J.S.B.T.: Dual-processing accounts of reasoning, judgment, and social cognition. Annu. Rev. Psychol. 59, 255-278 (2008).https://doi.org/10.1146/annurev.psych.59. 103006. 093629

42. McCusker, C.G.: Cognitive biases and addiction: an evolution in theory and method. Addiction 96(1), 47-56 (2002). https://doi.org/10.1046/j.1360-0443.2001.961474.x

43. Field, M., Mogg, K., Bradley, B.P.: Cognitive bias and drug craving in recreational cannabis users. Drug and alcohol dependence 74(1), 105-111 (2004). https://doi.org/10.1016/j.drugalcdep.2003.12.005

44. Scott, J.: Rational choice theory. Understanding contemporary society: Theories of the present 129, 671-685 (2000).

45. Becker, G.S., Murphy, K.M.: A theory of rational addiction. Journal of political Economy 96(4), 675-700 (1988). https://doi.org/10.1086/261558

46. Orphanides, A., Zervos, D.: Rational addiction with learning and regret. Journal of Political Economy 103(4), 739-758 (1995). https://doi.org/10.1086/262001

47. Fotuhi, O., Fong, G.T., Zanna, M.P., Borland, R., Yong, H.-H., Cummings, K.M.: Patterns of cognitive dissonance-reducing beliefs among smokers: a longitudinal analysis from the International Tobacco Control (ITC) Four Country Survey. Tobacco control 22(1), 52-58 (2013). http://dx.doi.org/10.1136/tobaccocontrol-2011-050139

48. Everitt, B.J., Robbins, T.W.: Neural systems of reinforcement for drug addiction: from actions to habits to compulsion. Nature neuroscience 8(11), 1481-1489 (2005). https:// doi.org/ 10.1038/nn1579

49. Baker, T.B., Piper, M.E., McCarthy, D.E., Majeskie, M.R., Fiore, M.C.: Addiction motivation reformulated: an affective processing model of negative reinforcement. Psychological review 111(1), 33 (2004). https://doi.org/10.1037/0033-295X.111.1.33

50. Khantzian, E.J.: The self-medication hypothesis of substance use disorders: A reconsideration and recent applications. Harvard review of psychiatry 4(5), 231-244 (1997). https:// doi.org/10.3109/10673229709030550

51. Walters, G.D.: Addiction and identity: Exploring the possibility of a relationship. Psychology of Addictive Behaviors 10(1), 9 (1996). https://doi.org/10.1037/0893-164X.10.1.9

52. Carver, C.S., Scheier, M.F.: On the self-regulation of behavior. Cambridge University Press, (2001) 
53. Webb, T.L., Sniehotta, F.F., Michie, S.: Using theories of behaviour change to inform interventions for addictive behaviours. Addiction 105(11), 1879-1892 (2010). https://doi.org/ 10.1111/j.1360-0443.2010.03028.x

54. De Ridder, D.T.D., Lensvelt-Mulders, G., Finkenauer, C., Stok, F.M., Baumeister, R.F.: Taking stock of self-control: A meta-analysis of how trait self-control relates to a wide range of behaviors. Personality and Social Psychology Review 16(1), 76-99 (2012). https://doi.org/10.1177/1088868311418749

55. Baumeister, R.F., Vonasch, A.J.: Uses of self-regulation to facilitate and restrain addictive behavior. Addictive behaviors 44, 3-8 (2015). https://doi.org/10.1016/j.addbeh.2014.09.011

56. Webb, T.L., Sheeran, P., Luszczynska, A.: Planning to break unwanted habits: Habit strength moderates implementation intention effects on behaviour change. British Journal of Social Psychology 48(3), 507-523 (2010). https://doi.org/10.1348/014466608X370591

57. Oei, T.P., Baldwin, A.R.: Expectancy theory: a two-process model of alcohol use and abuse. Journal of studies on alcohol 55(5), 525-534 (1994).https://doi.org/10.15288/ jsa.1994.55. 525

58. Kobus, K.: Peers and adolescent smoking. Addiction 98, 37-55 (2003). https://doi.org/ 10.1046/j.1360-0443.98.s1.4.x

59. Asch, S.E.: Studies of independence and conformity: I. A minority of one against a unanimous majority. Psychological Monographs: General and Applied 70(9), 1-70 (1956). https://doi.org/10.1037/h0093718

60. Cialdini, R.B., Trost, M.R.: Social influence: Social norms, conformity and compliance. In: The handbook of social psychology, Vols. 1-2, 4th ed. pp. 151-192. McGraw-Hill, New York, NY, US (1998)

61. Borsari, B., Carey, K.B.: Descriptive and injunctive norms in college drinking: a meta-analytic integration. Journal of studies on alcohol 64(3), 331-341 (2003). https://doi.org/ 10.15288/jsa.2003.64.331

62. Dingle, G.A., Cruwys, T., Frings, D.: Social identities as pathways into and out of addiction. Frontiers in psychology 6, 1795 (2015). https://doi.org/10.3389/fpsyg.2015.01795

63. Smedley, B.D., Syme, S.L.: Committee on capitalizing on social science and behavioral research to improve the public's health. Promoting health: intervention strategies from social and behavioral research. Am J Health Promot 15(3), 149-166 (2001).

64. Chaloupka, F.J.: Contextual factors and youth tobacco use: policy linkages. Addiction 98, 147-149 (2003). https://doi.org/10.1046/j.1360-0443.98.s1.10.x

65. Goldstein, R.Z., Volkow, N.D.: Drug addiction and its underlying neurobiological basis: neuroimaging evidence for the involvement of the frontal cortex. American Journal of Psychiatry 159(10), 1642-1652 (2002). https://doi.org/10.1176/appi.ajp.159.10.1642

66. Baumeister, R.F., Heatherton, T.F.: Self-regulation failure: An overview. Psychological inquiry 7(1), 1-15 (1996). https://doi.org/10.1207/s15327965pli0701_1

67. Weinstein, A., Maraz, A., Griffiths, M.D., Lejoyeux, M., Demetrovics, Z.: Chapter 98 Compulsive Buying-Features and Characteristics of Addiction. In: Preedy, V.R. (ed.) Neuropathology of Drug Addictions and Substance Misuse. pp. 993-1007. Academic Press, San Diego (2016). https://doi.org/10.1016/B978-0-12-800634-4.00098-6

68. Molet, M., Miller, R.R.: Timing: An attribute of associative learning. Behavioural processes 101, 4-14 (2014). https://doi.org/10.1016/j.beproc.2013.05.015

69. Parke, J., Griffiths, M.D.: The role of structural characteristics in gambling. In., pp. 211243. Elsevier, New York (2007)

70. Kahneman, D.: Thinking, fast and slow. Macmillan, (2011)

71. Chóliz, M.: Cognitive biases and decision making in gambling. Psychological reports 107(1), 15-24 (2010). https://doi.org/10.2466/02.09.18.22.PR0.107.4.15-24 
72. Csikszentmihalyi, M., Csikzentmihaly, M.: Flow: The psychology of optimal experience, vol. 1990. Harper \& Row New York, (1990)

73. Webster, J., Trevino, L.K., Ryan, L.: The dimensionality and correlates of flow in humancomputer interactions. Computers in human behavior 9(4), 411-426 (1993). https://doi.org/ 10.1016/0747-5632(93)90032-N

74. Khang, H., Kim, J.K., Kim, Y.: Self-traits and motivations as antecedents of digital media flow and addiction: The Internet, mobile phones, and video games. Computers in Human Behavior 29(6), 2416-2424 (2013). https://doi.org/10.1016/j.chb.2013.05.027

75. Gable, R.A., Hester, P.H., Rock, M.L., Hughes, K.G.: Back to basics: Rules, praise, ignoring, and reprimands revisited. Intervention in School and Clinic 44(4), 195-205 (2009).

76. Mei, S., Yau, Y.H.C., Chai, J., Guo, J., Potenza, M.N.: Problematic Internet use, well-being, self-esteem and self-control: Data from a high-school survey in China. Addictive behaviors 61, 74-79 (2016). https://doi.org/10.1177/1053451208328831

77. Sioni, S.R., Burleson, M.H., Bekerian, D.A.: Internet gaming disorder: Social phobia and identifying with your virtual self. Computers in Human Behavior 71, 11-15 (2017). https://doi.org/10.1016/j.chb.2017.01.044

78. Han, D.H., Lee, Y.S., Yang, K.C., Kim, E.Y., Lyoo, I.K., Renshaw, P.F.: Dopamine genes and reward dependence in adolescents with excessive internet video game play. Journal of addiction medicine 1(3), 133-138 (2007). https://doi.org/10.1097/ADM.0b013e31811f465f

79. Cash, H., D. Rae, C., H. Steel, A., Winkler, A.: Internet Addiction: A Brief Summary of Research and Practice. Current Psychiatry Reviews 8(4), 292-298 (2012). https://doi.org/10.2174/157340012803520513

80. Griffiths, M.: Fruit machine gambling: The importance of structural characteristics. Journal of gambling studies 9(2), 101-120 (1993). https://doi.org/10.1007/BF01014863

81. Berthon, P., Pitt, L., Campbell, C.: Addictive De-Vices: A Public Policy Analysis of Sources and Solutions to Digital Addiction. Journal of Public Policy \& Marketing 38(4), 451-468 (2019). https://doi.org/10.1177/0743915619859852

82. Ainslie, G., Monterosso, J.: Chapter 2 - Hyperbolic Discounting as a Factor in Addiction: A critical Analysis. In: Vuchinich, R.E., Heather, N. (eds.) Choice, Behavioural Economics and Addiction. pp. 35-69. Pergamon, Amsterdam (2003). https://doi.org/10.1016/B978008044056-9/50043-9

83. Du, J., Kerkhof, P., van Koningsbruggen, G.M.: Predictors of social media self-control failure: Immediate gratifications, habitual checking, ubiquity, and notifications. Cyberpsychology, Behavior, and Social Networking 22(7), 477-485 (2019). https://doi.org/10.1089/ cyber.2018.0730

84. LaRose, R., Lin, C.A., Eastin, M.S.: Unregulated Internet usage: Addiction, habit, or deficient self-regulation? Media Psychology 5(3), 225-253 (2003). https://doi.org/ 10.1207/ S1532785XMEP0503_01

85. Alavi, S.S., Ferdosi, M., Jannatifard, F., Eslami, M., Alaghemandan, H., Setare, M.: Behavioral addiction versus substance addiction: Correspondence of psychiatric and psychological views. International journal of preventive medicine 3(4), 290 (2012).

86. Limayem, M., Hirt, S.G., Cheung, C.M.K.: How habit limits the predictive power of intention: The case of information systems continuance. MIS quarterly, 705-737 (2007). https://doi.org/10.2307/25148817

87. Fogg, Brian J. "A behavior model for persuasive design." Proceedings of the 4th international Conference on Persuasive Technology. (2009). https://doi.org/ 10.1145/ 1541948. 1541999 
88. Osatuyi, B., Turel, O.: Tug of war between social self-regulation and habit: Explaining the experience of momentary social media addiction symptoms. Computers in Human Behavior 85, 95-105 (2018). https://doi.org/10.1016/j.chb.2018.03.037

89. Ames, M.G.: Managing mobile multitasking: the culture of iPhones on stanford campus. Paper presented at the Proceedings of the 2013 conference on Computer supported cooperative work, San Antonio, Texas, USA. https://doi.org/10.1145/2441776.2441945

90. Kalman, Y.M., Rafaeli, S.: Online pauses and silence: Chronemic expectancy violations in written computer-mediated communication. Communication Research 38(1), 54-69 (2011). https://doi.org/10.1177/0093650210378229

91. Alutaybi, A., Arden-Close, E., McAlaney, J., Stefanidis, A., Phalp, K., Ali, R.: How Can Social Networks Design Trigger Fear of Missing Out? In: 2019 IEEE International Conference on Systems, Man and Cybernetics (SMC), 6-9 Oct. 2019 2019, pp. 3758-3765 https://doi.org/ 10.1109/SMC.2019.8914672.

92. Alutaybi, A., Al-Thani, D., McAlaney, J., Ali, R.: Combating Fear of Missing Out (FoMO) on Social Media: The FoMO-R Method. International journal of environmental research public health 17(17), 6128 (2020). https://doi.org/ https://doi.org/10.3390/ijerph17176128

93. Gomez-Uribe, C.A., Hunt, N.: The Netflix Recommender System: Algorithms, Business Value, and Innovation. 6(4\%J ACM Trans. Manage. Inf. Syst.), Article 13 (2016). https://doi.org/10.1145/2843948

94. Siles, I., Espinoza-Rojas, J., Naranjo, A., \& Tristán, M. F.:The Mutual Domestication of Users and Algorithmic Recommendations on Netflix. Communication, Culture and Critique, 12(4), 499-518 (2019). https://doi.org/ 10.1093/ccc/tcz025

95. Navazio, R.: An Experimental Approach to Bandwagon Research. Public Opinion Quarterly 41(2), 217-225 (1977). https://doi.org/10.1086/268376

96. Cialdini, R.B.: Harnessing the science of persuasion. Harvard business review 79(9), 72-81 (2001).

97. Nisbett, R.E., Wilson, T.D.: The halo effect: Evidence for unconscious alteration of judgments. Journal of Personality and Social Psychology 35(4), 250-256 (1977). https://doi.org/ 10.1037/0022-3514.35.4.250

98. Sulkunen, P.: Images of addiction: Representations of addictions in films. Addiction Research \& Theory 15(6), 543-559 (2007). https://doi.org/10.1080/16066350701651255

99. Fogg, B.J.: Persuasive technology: using computers to change what we think and do. Ubiquity 2002(December), 2 (2002). https://doi.org/ 10.1145/764008.763957

100. Vaghefi, I., Lapointe, L., Boudreau-Pinsonneault, C.: A typology of user liability to IT addiction. Information Systems Journal 27(2), 125-169 (2017). https://doi.org/10.1111/ isj. 12098

101. Bandura, A.: Social learning theory. Prentice-hall, (1977)

102. Gunuc, S.: Peer influence in Internet and digital game addicted adolescents: is Internet/digital game addiction contagious. Int J High Risk Behav Addict 6(2), e33681 (2017). https://doi.org/10.5812/ijhrba.33681

103. Vogel, E.A., Rose, J.P., Okdie, B.M., Eckles, K., Franz, B.: Who compares and despairs? The effect of social comparison orientation on social media use and its outcomes. Personality and Individual Differences 86, 249-256 (2015). https://doi.org/10.1016/j.paid.2015.06.026

104. Yang, C.-c.: Instagram use, loneliness, and social comparison orientation: Interact and browse on social media, but don't compare. Cyberpsychology, Behavior, and Social Networking 19(12), 703-708 (2016). https://doi.org/10.1089/cyber.2016.0201

105. Cialdini, R.B., Reno, R.R., Kallgren, C.A.: A focus theory of normative conduct: recycling the concept of norms to reduce littering in public places. Journal of personality and social psychology 58(6), 1015 (1990). https://doi.org/10.1037/0022-3514.58.6.1015 
106. Wang, Y., Wu, A.M.S., Lau, J.T.F.: The health belief model and number of peers with internet addiction as inter-related factors of Internet addiction among secondary school students in Hong Kong. BMC Public Health 16(1), 272 (2016). https://doi.org/10.1186/s12889016-2947-7

107. Yee, N.: The Psychology of Massively Multi-User Online Role-Playing Games: Motivations, Emotional Investment, Relationships and Problematic Usage. In: Schroeder, R., Axelsson, A.-S. (eds.) Avatars at Work and Play: Collaboration and Interaction in Shared Virtual Environments. pp. 187-207. Springer Netherlands, Dordrecht (2006). https://doi.org/ 10.1007/1-4020-3898-4_9

108. Klemm, C., Pieters, W.: Game mechanics and technological mediation: an ethical perspective on the effects of MMORPG's. Ethics and Information Technology 19(2), 81-93 (2017). https://doi.org/10.1007/s10676-017-9416-6

109. Festinger, L.: A theory of social comparison processes. Human relations 7(2), 117-140 (1954). https://doi.org/10.1177/001872675400700202

110. Fong, M., Zhao, K., Smillie, L.D.: Personality and competitiveness: Extraversion, agreeableness, and their aspects, predict self-reported competitiveness and competitive bidding in experimental auctions. Personality and Individual Differences 169, 109907 (2021). https://doi.org/10.1016/j.paid.2020.109907

111. Luchner, A.F., Houston, J.M., Walker, C., Alex Houston, M.: Exploring the relationship between two forms of narcissism and competitiveness. Personality and Individual Differences 51(6), 779-782 (2011). https://doi.org/10.1016/j.paid.2011.06.033

112. Hussain, Z., Griffiths, M.D.: The attitudes, feelings, and experiences of online gamers: A qualitative analysis. CyberPsychology \& Behavior 12(6), 747-753 (2009). https://doi.org/ 10.1089/cpb.2009.0059

113. Gonzales, A.L., Hancock, J.T.: Mirror, mirror on my Facebook wall: Effects of exposure to Facebook on self-esteem. Cyberpsychology, behavior, and social networking 14(1-2), 7983 (2011). https://doi.org/10.1089/cyber.2009.0411

114. Martin, I.M., Kamins, M.A., Pirouz, D.M., Davis, S.W., Haws, K.L., Mirabito, A.M., Mukherjee, S., Rapp, J.M., Grover, A.: On the road to addiction: The facilitative and preventive roles of marketing cues. Journal of Business Research 66(8), 1219-1226 (2013). https://doi.org/10.1016/j.jbusres.2012.08.015 